\title{
Clinical and pharmacologic aspects of blinatumomab in the treatment of B-cell acute lymphoblastic leukemia
}

This article was published in the following Dove Press journal:

Clinical Pharmacology:Advances and Applications

II April 2013

Number of times this article has been viewed

\author{
Craig A Portell \\ Candice MWenzell \\ Anjali S Advani \\ Leukemia Program, Taussig Cancer \\ Institute, Cleveland Clinic, Cleveland, \\ $\mathrm{OH}$, USA
}

\begin{abstract}
Acute lymphoblastic leukemia (ALL) in adults remains a challenging disease to treat, and novel therapies are needed. Precursor-B ALL comprises $80 \%$ of cases, and the CD19 antigen is expressed in nearly all precursor-B ALL patients. Bispecific T-cell-engaging antibodies are novel bioengineered proteins. The bispecific T-cell-engaging antibody blinatumomab engages polyclonal T cells to CD19-expressing B cells. By binding to both CD3 and CD19, blinatumomab physically brings these $\mathrm{T}$ cells in close proximity to malignant $\mathrm{B}$ cells and potentiates T-cellinduced cytotoxic cell kill. Blinatumomab requires continuous intravenous infusion due to its short half-life, the need for continuous exposure for the drug to exert sufficient efficacy, and lessened toxicity. A phase II trial of B-cell ALL patients with persistent or relapsed minimal residual disease demonstrated an $80 \%$ rate of complete molecular remission. Cytokine-release syndrome and central nervous system events, such as seizures and encephalopathy, are reversible toxicities. Promising results in B-cell ALL with minimal residual disease have led to further evaluation of this drug in newly diagnosed and relapsed B-cell ALL.
\end{abstract}

Keywords: blinatumomab, B-cell acute lymphoblastic leukemia, CD19, BiTE antibodies

\section{Introduction}

Acute lymphoblastic leukemia (ALL) is an aggressive lymphoid malignancy characterized by replacement of the bone marrow compartment with blasts. Extramedullary presentations in the central nervous system (CNS), lymph nodes, gonads, spleen, and liver can also be seen. Precursor B-cell (pre-B) ALL is the most common phenotype and comprises $80 \%$ of cases. ${ }^{1}$ Initial treatment of B-cell ALL involves an intensive, multiagent chemotherapy regimen followed by a consolidation phase with high-dose chemotherapy. A second intensive regimen is often employed, followed by 2-3 years of low-dose oral maintenance chemotherapy in those not proceeding to allogeneic hematopoietic stem cell transplant (HSCT). Prophylaxis of the CNS with intrathecal and high-dose chemotherapy is required due to a frequent relapse rate in the CNS without prophylactic treatment. Despite a high complete response (CR) rate (80\%-90\%), only $20 \%-40 \%$ of adult patients will remain in remission at 5 years. ${ }^{2,3}$ Minimal residual disease (MRD) can be measured by flow cytometry or polymerase chain reaction (PCR), and persistent MRD is correlated with an increased risk of relapse and decreased overall survival in patients who have achieved a CR. ${ }^{4}$ At the time of morphologic relapse, the prognosis is dismal, with a 5-year overall survival of only $7 \% .^{5}$ Therefore, novel treatment strategies are needed. The CD19 antigen is expressed on nearly all pre-B ALL patients, ${ }^{6,7}$ and therefore CD19 represents an attractive therapeutic target. 
Blinatumomab (previously MT103 or MEDI-538) is a bispecific T-cell-engaging (BiTE) antibody against CD19. BiTE antibodies are genetically engineered single-chain antibodies that use a linker combining two variable regions of a normal antibody with different specificities (Figure 1). This eliminates the constant regions of these antibodies and allows for close approximation of two antigens. By making one of the variable regions on the BiTE antibody specific to T cells, BiTE antibodies are thought to initiate a T-cell cytotoxic response to the other antigen. ${ }^{8}$ In the case of blinatumomab, T-cell-specific CD3 and B-cell-specific CD19 are brought in close proximity. This promotes an antitumor response against CD19-expressing B cells that does not require T-cell specificity to the tumor. ${ }^{8}$ Thus, the antitumor response is from a polyclonal T-cell population, allowing more $\mathrm{T}$ cells to engage in the antitumor response. ${ }^{8}$ By not targeting the major histocompatibility complex, often downregulated on tumor cells, ${ }^{1,9}$ BiTE antibodies direct a T-cell-specific cytotoxic response, irrespective of tumor immune escape mechanisms. This review will focus on blinatumomab in the treatment of B-cell ALL.

\section{19: the ligand}

CD19, a B-lymphocyte-specific molecule, is the target of blinatumomab. CD19 is expressed in early lymphocyte development (blast stage) through the mature memory B lymphocyte or marginal zone B lymphocyte. However, CD19 expression is lost after plasma cell differentiation. ${ }^{2,3,10} \mathrm{CD} 19$ is highly conserved in B-cell malignancies, including most B-cell ALL. ${ }^{1,4}$ The receptor is a $96 \mathrm{kDa}$ transmembrane protein consisting of two extracellular immunoglobulin-like domains $^{5,11,12}$ and an extensive cytoplasmic tail containing numerous tyrosine residues. ${ }^{67,13}$ In mature B lymphocytes, the normal function of CD19 is as a costimulatory molecule of the B-cell receptor along with CD21 and CD81.8,14 After complement binding (specifically, C3d) to CD21, CD19 is phosphorylated and acts as a membrane tyrosine kinase. After activation by phosphorylation, CD19 activates downstream targets, including members of the Syc family, phosphoinositol-3 kinase, and phospholipase- $\mathrm{C} \gamma 2$, and thus promotes activation and differentiation of normal B cells. ${ }^{8,15,16}$ Patients with somatic homozygous CD19 loss-of-function mutations phenotypically present with hypogammaglobulinemia and recurrent infections but normal appearing circulating lymphocytes. ${ }^{8,17}$ These patients have a loss of normal differentiation to memory B lymphocytes and impaired humoral immunity. While CD19 function in mature B lymphocytes is clearly costimulatory with the B-cell receptor, its function in immature B lymphocytes is less clear.

A

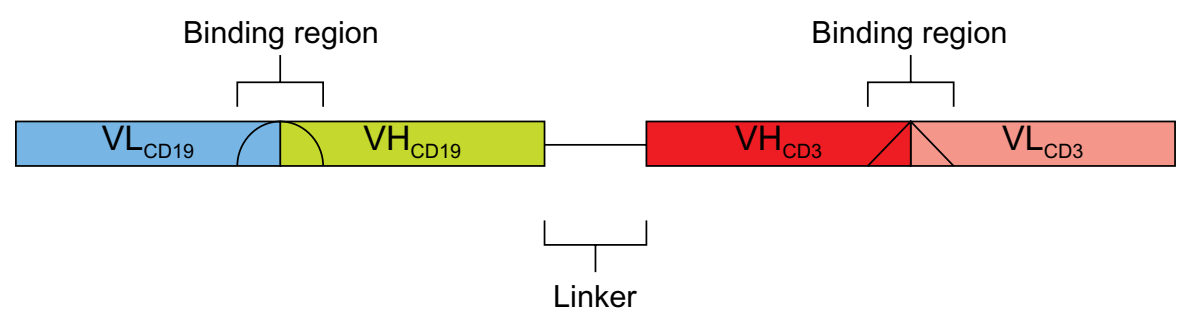

B

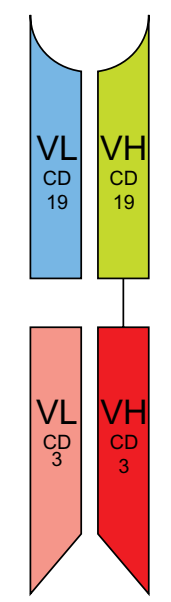

Figure I (A and B) Diagram of blinatumomab structure ${ }^{30}$ consisting of variable heavy $\left(\mathrm{VH}_{\mathrm{CDI}}\right)$ and light $\left(\mathrm{VL}_{\mathrm{CDI9}}\right)$ chains of anti-CDI9 connected by a five-amino acid, nonimmunogenic linker to variable heavy $\left(\mathrm{VH}_{\mathrm{CD} 3}\right)$ and light $\left(\mathrm{VL}_{\mathrm{CD} 3}\right)$ chains of anti-CD3. (A) Linear pattern; $(\mathbf{B})$ schematic of assembled protein. 
Uckun et al recently reported the cloning and characterization of a $54 \mathrm{kDa}$ high-mobility group protein as the ligand for the human pan-B-cell coreceptor CD19. ${ }^{18}$ Engagement of the CD19 coreceptor on B-cell ALL cells with CD19 ligand disrupted the CD19-associated signaling network, altered the expression levels of multiple genes directly involved in the regulation of apoptosis, and triggered rapid death in a CD19-specific manner. ${ }^{18}$ Cytotoxic T cells transduced with chimeric anti-CD19 receptors also prevent engraftment of primary lymphoblastic leukemia in vivo, further stressing the importance of CD19 as a potential "driver" in ALL. ${ }^{19}$ The CD19 receptor is not shed from the cell surface and undergoes antibody-induced internalization, ${ }^{20}$ also making it an attractive target.

The murine anti-CD19 immunoglobulin G antibody HD37 demonstrated cytotoxic activity in three pre-B-cell ALL cell lines (NALM-6-UM1, REH, and JM-1), independent of complement and effector cells. ${ }^{21}$ This death was partly due to induction of apoptosis. The increase in apoptosis noted at the higher concentrations was postulated to be related to enhanced negative intracellular signaling through dimerization of the CD19 antigen. ${ }^{21}$ In lymphoma cell lines, HD37 binding to the CD19 surface was also able to inhibit the function of the P-glycoprotein pump ${ }^{22}$ and induce cell-cycle arrest. ${ }^{23}$ These studies further support targeting CD19 in B-cell ALL.

\section{Blinatumomab: chemistry}

Blinatumomab's name is derived from "B-lineage-specific antitumor mouse monoclonal antibody." ${ }^{8}$ Unlike other commercially available monoclonal antibodies, blinatumomab is a fusion protein made up of the variable regions of two single-chain monoclonal antibodies (scFvs) - CD19 and CD3 (on T cells) - recombinantly linked by a nonimmunogenic five-amino acid chain $^{8}$ (Figure 1). This linker allows for a high degree of rotation flexibility, which may be needed for binding each of the CD19 and CD3 epitopes on cell membranes. ${ }^{8}$ Blinatumomab is approximately one-third of the size of traditional monoclonal antibodies at a size of $55 \mathrm{kDa}$ and is not glycosylated. ${ }^{8,24}$ The CD19-expressing lymphoblasts are linked to the CD3expressing $\mathrm{T}$ cells and are subject to perforin-mediated cytotoxicity. ${ }^{25}$ One particular challenge with the bispecific antibody construct is to activate polyclonal $\mathrm{T}$ cells through the CD3-signaling complex in a controlled manner that is sensitive and dependent on the presence of the target (CD19 in this case). Otherwise, production of inflammatory cytokines and secondary reactions can be problematic. ${ }^{26}$
New engineering strategies for bispecific antibodies will continue to improve this platform by increasing specificity, stability, and efficacy. ${ }^{27}$

\section{Preclinical observations}

Preclinical studies with blinatumomab demonstrated enhanced T-cell cytotoxicity specific to CD19-expressing $B$ cells both in vivo and in vitro. When cocultured with the CD19-expressing pre-B lymphoma cell line NALM-6 and CD8-expressing T cells, blinatumomab increased cell contact with T and NALM- 6 cells, inducing increased apoptosis and lysis of NALM-6 cells. ${ }^{28}$ Cell lysis was not observed in CD19-negative malignancies - specifically, an erythroleukemia cell line ${ }^{28}$ and a colon cancer cell line ${ }^{29}$ - suggesting that CD3 binding by blinatumomab alone is insufficient to induce T-cell activation. Inhibiting perforin activation eliminates blinatumomab-induced cytotoxicity, suggesting that the perforin-containing cytotoxic $\mathrm{T}$ cell is required for efficacy. ${ }^{30} \mathrm{~T}$-cell-mediated cell lysis was maintained in the absence of major histocompatibility complex class I expression by CD19-expressing B cells. ${ }^{31}$

Autologous peripheral blood T-cell-induced B-cell lysis has been demonstrated in in vitro models outside of cell lines, both in normal healthy donor peripheral B cells and in chronic lymphocytic leukemia B-cell patient samples. ${ }^{32}$ A single cytotoxic $\mathrm{T}$ cell can induce cell lysis and apoptosis of multiple B-cell lymphoma cells in culture, depending on the amount of time allowed for coculture and the ratio of cytotoxic T cells to target cells. ${ }^{28}$ Blinatumomab also increases inflammatory cytokine production, specifically interleukin (IL)-2, tumor necrosis factor- $\alpha$, interferon- $\gamma$, IL-6, IL-10, and IL-4, when placed in culture with CD8-expressing T cells and CD19-expressing lymphoma cell lines. ${ }^{33}$ The role of cytokine production remains unclear. When cytokine expression is eliminated with coadministration of dexamethasone, there is no change in cell lysis and apoptosis of B-cell lymphoma cell lines. ${ }^{33}$

In vivo, blinatumomab administered daily for 5 days immediately after coinjection with B-lymphoma cell lines and healthy donor, unstimulated, human peripheral blood mononuclear cells (PBMCs) containing $\mathrm{CD}^{+} \mathrm{T}$ cells induced a drug dose-dependent and PBMC dose-dependent tumorgrowth suppression in a severe combined immunodeficient mouse model. ${ }^{34}$ Those mice treated with blinatumomab had longer survival and smaller tumors than those treated with PBMCs alone or with a different BiTE antibody against the epithelial cell-adhesion molecule protein, an epithelial cellsurface antigen. ${ }^{34}$ 


\section{Clinical pharmacology}

Pharmacokinetic studies of blinatumomab were conducted in patients receiving a 4-week continuous infusion. ${ }^{35}$ The mean ( \pm standard deviation $[\mathrm{SD}]$ ) steady-state serum concentration of blinatumomab is $731 \pm 163 \mathrm{pg} / \mathrm{mL}$ and is reached within 1 day. The steady-state serum concentration is similar with subsequent cycles (cycles 2-4). The volume of distribution is $1.61 \pm 0.74 \mathrm{~L} / \mathrm{m}^{2}$, and mean $( \pm \mathrm{SD}$ ) clearance of blinatumomab is $22.3 \pm 5 \mathrm{~L} / \mathrm{day} / \mathrm{m}^{2}$. Blinatumomab has a short elimination half-life (mean \pm SD) of $1.25 \pm 0.63$ hours. Due to its short half-life and relatively high clearance, it is presumed to be eliminated renally. ${ }^{35}$ No human antimouse antibodies that would neutralize blinatumomab have been detected..$^{25}$

The pharmacodynamic effects of blinatumomab are interesting. Within the first few hours after administration of blinatumomab, there is a rapid transient decrease in $\mathrm{T}$ cells, followed by an accelerated increase in $\mathrm{T}$ cells exceeding baseline values. ${ }^{25,35}$ The initial fall in T cells is attributed to a redistribution phenomenon thought to be caused by an increased adhesion of $\mathrm{T}$ cells to the endothelium of the blood, triggered by monovalent binding of blinatumomab to $\mathrm{CD} 3 .{ }^{35}$ Following the nadir, T cells expand, likely due to stimulation by subsequent cytokine release. Additionally, $\mathrm{B}$ cells rapidly decrease in less than a day, are below the limit of detection in less than 2 days, and remain undetectable for the duration of the blinatumomab infusion. This latter phenomenon is attributed to B-cell apoptosis. ${ }^{35}$ The low dose of blinatumomab needed for response (compared with conventional antibodies) is likely related to the high lytic potential of cytotoxic $T$ cells. These $T$ cells are activated by engagement of only a few $\mathrm{CD} 3$ receptor subunits, can rapidly adopt a serial lysis mode, and can proliferate at the site of their activation..$^{25}$

Due to the relatively short half-life of blinatumomab and its mechanism of action, blinatumomab is administered as a continuous intravenous infusion over a minimum of 4 weeks. ${ }^{8}$ When administered in this fashion, drug levels achieved are sustained, predictable, and show dose linearity. ${ }^{8}$ In addition, when shorter infusions (over 2 or 4 hours) were utilized in early trials, patients experienced a high rate of adverse events, such as neurologic events, cytokine-release syndrome, and infections, leading to early discontinuation of these trials. ${ }^{8}$ Although the infusion goes over several weeks, it can be administered in the outpatient setting via an implanted port and minipump system. ${ }^{8}$ In clinical trials, patients were monitored as inpatients for 3-7 days at the start of each course to observe for infusion reactions. ${ }^{8}$

\section{Clinical toxicities}

Blinatumomab has been evaluated in B-cell non-Hodgkin's lymphoma (NHL) ${ }^{25}$ and in B-cell ALL. ${ }^{36-38}$ Cytokine-release syndrome, usually characterized by fevers and chills, and hypotension and shortness of breath in severe cases, is a known adverse event with blinatumomab. This syndrome has been attributed to rapid malignant cell kill by $\mathrm{T}$ lymphocytes during the initial infusion. ${ }^{35}$ Fever can be seen in up to $70 \%$ of patients treated with blinatumomab..$^{25,36,38}$ Pretreatment with steroids can decrease the severity of this syndrome. ${ }^{33}$ Months of treatment with blinatumomab did not lead to signs of uncontrolled T-cell activation nor signs of T-cell anergy. ${ }^{25,36,38}$ As blinatumomab is thought to target all CD19-expressing cells, normal B lymphocytes are not spared. Thus, leukopenia and hypogammaglobuminemia can be seen in up to $70 \%$ of patients. ${ }^{25,36,38} \mathrm{An}$ increased risk of infection may occur, although it is difficult to determine whether this is related to prior therapy or the underlying NHL or ALL. In the NHL cohort of 39 patients, one death from bacterial sepsis and one case of pneumonia without death occurred. ${ }^{25}$ In the cohort of 21 patients with MRD-positive B-cell ALL, four patients had infectious events, including two with catheter related events, one with Gram-negative sepsis, and one with pneumonia. ${ }^{38}$ In the relapsed B-cell ALL cohort of 36 patients, one death was reported related to fungal sepsis. ${ }^{36}$

CNS events have been reported in $15 \%-20 \%$ of patients treated with blinatumomab and can be severe..$^{25,36,38}$ There have been a total of 16 reported CNS events in the total of 95 patients reported, including seizure or convulsions $(n=8)$, encephalopathy or confusion $(n=6)$, and cerebellar symptoms $(\mathrm{n}=2)$. All events were reversible with a withholding drug..$^{25,36,38}$ In the relapsed ALL cohort, six patients with CNS events (three seizures and three encephalopathy) were rechallenged with blinatumomab at lower doses. ${ }^{36}$ Four of these six patients had no recurrence of CNS events at the lower doses. The remaining two had recurrence and were not rechallenged after recurrence. ${ }^{36}$

\section{Clinical response}

The first clinical trial in blinatumomab was in indolent NHL. ${ }^{25}$ A phase I dose-escalation study was performed with six different cohorts $\left(0.5,1.5,5,15,30\right.$, and $60 \mu \mathrm{g} / \mathrm{m}^{2} / 24$ hours $)$ as a continuous infusion for 4 weeks followed by a 2-week break (one cycle is 6 weeks). Patients were treated for a maximum of three cycles. Thirty-eight patients were enrolled. All responses occurred at dose levels $15 \mu \mathrm{g} / \mathrm{m}^{2} / 24$ hours and higher, suggesting a dose-response relationship. ${ }^{25}$ Eleven responses occurred (overall response rate $28.9 \%$ ), four CR 
and seven partial responses by standard criteria. ${ }^{39}$ Tumor shrinkage not reaching standard partial-response criteria was seen in an additional eleven patients. This study identified the optimal dose as $15 \mu \mathrm{g} / \mathrm{m}^{2} / 24$ hours as a continuous infusion for 4 weeks with a 2 -week break.

After the initial NHL trial, focus switched to ALL. The German group evaluated blinatumomab in patients with $\mathrm{CR}$ but measurable MRD after induction chemotherapy. ${ }^{37,38}$ The presence of MRD is defined according to the sensitivity of the assay, typically greater than $10^{-4}$ transcripts by PCR. ${ }^{4}$ PCR measures rearrangements of the T-cell receptor or immunoglobulin gene. ${ }^{4}$ In Brüggemann et al's study, the presence of MRD until week 16 predicted a 3-year hematologic relapse rate of $94 \%$. Thus the persistence of MRD after induction chemotherapy identifies a high-risk population for recurrent disease.

The German group treated 21 patients with B-cell ALL in a hematologic remission but with detectable MRD in a phase II clinical trial of blinatumomab. ${ }^{37,38}$ Only 20 patients were evaluated for outcomes, as one patient had a seizure in the first cycle and did not receive further therapy. Persistence of MRD after induction chemotherapy was present in 15 of the 21 patients enrolled (MRD-refractory). The other five patients had been previously MRD-negative but later had detectable MRD without hematologic relapse (MRD relapse). Patients were treated with $15 \mu \mathrm{g} / \mathrm{m}^{2} / 24$ hours continuous infusion of blinatumomab for 4 out of 6 weeks for four cycles. Eighty percent of patients achieved a complete molecular remission (negative MRD) after the first cycle, with a hematologic relapse-free survival of 19.1 months in the 16 responders and 3.2 months in the four nonresponders, with a median follow-up of 33 months. ${ }^{37,38}$ Allogeneic HSCT was successfully performed in nine patients who had suitable donors. Six of the nine patients remained in a CR after transplant, with two relapses and one death due to graft-versus-host disease. Of the eleven patients who did not undergo allogeneic transplant, six remained in CR. One patient withdrew consent and was not followed; the other four patients relapsed..$^{37,38}$ These results are encouraging for a poor-risk group of patients. At this point, the study is not mature enough to make a recommendation regarding allogeneic HSCT in patients achieving a complete molecular remission with blinatumomab.

The German group has also evaluated blinatumomab in 36 patients with relapsed or refractory B-cell ALL in a phase II trial. ${ }^{36}$ Three cohorts were evaluated in an intrapatient dose-escalation manner. The optimal dose was determined to be $5 \mu \mathrm{g} / \mathrm{m}^{2} / 24$ hours in week 1 and $15 \mu \mathrm{g} / \mathrm{m}^{2} / 24$ hours on subsequent weeks and cycles. Due to a high tumor burden, cytokine-release syndrome and CNS events were common at higher doses during initial treatment. ${ }^{36}$ This necessitated decreasing the initial dose. Hematologic CR was achieved in $72 \%(n=26)$. The achievement of CR was more common in patients with first relapse (95\% CR rate, 20 out of 21 patients) than those treated after subsequent relapse $(40 \% \mathrm{CR}$ rate, six out of 15 patients). Allogeneic HSCT was performed in 13 of the 26 responders, with all but one remaining in $\mathrm{CR}$ at the time of report (median follow-up 10.7 months). ${ }^{36}$ One patient treated with allogeneic HSCT relapsed with CD19-negative B-cell ALL. Of the other 13 responders not receiving an allogeneic $\mathrm{HSCT}$, eight (61.5\%) relapsed. Two of these relapsed with CD19-negative B-cell ALL, suggesting a potential mechanism of resistance to blinatumomab. Overall, median survival was 9.8 months, with a 14.1-month median survival in responders. ${ }^{36}$ These results are encouraging, compared to the median survival of 24 weeks in relapsed ALL with chemotherapy. ${ }^{5}$

\section{Closing remarks}

The BiTE antibody blinatumomab is a novel agent for treatment of B-cell malignancies, and particularly B-cell ALL. It has a favorable safety profile, although reversible CNS events (mostly seizures and encephalopathy) and cytokinerelease syndrome can occur. CNS events resolve after holding the drug. Cytokine-release syndrome is decreased by initial cytoreduction and pretreatment with steroids. Unfortunately, the short half-life, high clearance, and mechanism of action require continuous intravenous infusion for optimal efficacy. This can often be accomplished in the outpatient setting with a central venous catheter and infusion pump. Blinatumomab has demonstrated encouraging response rates in the setting of MRD ( $80 \%$ complete molecular remission rate) and in the relapsed setting ( $72 \%$ complete hematologic remission rate). Blinatumomab is currently being further evaluated in a multicenter trial for relapsed B-cell ALL. Given the encouraging results with blinatumomab in the setting of MRD and the durable remissions, national cooperative groups in the US are embarking on a clinical trial, E1910, incorporating blinatumomab in newly diagnosed adult ALL patients. Patients will be randomized to receive or not to receive two cycles of blinatumomab after induction chemotherapy and will be stratified according to the presence of MRD after the initial cycle of chemotherapy. Patients in the blinatumomab arm will continue to receive further cycles of blinatumomab interspersed with the remainder of their chemotherapy. If this study demonstrates superiority in the blinatumomab arm, such a study may lead to FDA approval of the drug. 


\section{Acknowledgment}

The authors would like to thank the Cleveland Clinic Department of Medical Art and Photography for assisting with the figures.

\section{Disclosure}

The authors report no conflicts of interest in this work.

\section{References}

1. Swerdlow S, Campo E, Harris NL, et al, editors. WHO Classification of Tumours of Haematopoietic and Lymphoid Tissue (IARC WHO Classification of Tumours), 4th ed. Geneva: World Health Organization; 2008.

2. Stock W, Johnson JL, Stone RM, et al. Dose intensification of daunorubicin and cytarabine during treatment of adult acute lymphoblastic leukemia: results of Cancer and Leukemia Group B Study 19802. Cancer. 2013;119(1):90-98.

3. Thomas DA, O'Brien S, Faderl S, et al. Chemoimmunotherapy with a modified hyper-CVAD and rituximab regimen improves outcome in de novo Philadelphia chromosome-negative precursor B-lineage acute lymphoblastic leukemia. J Clin Oncol. 2010;28(24):3880-3889.

4. Brüggemann M, Raff T, Flohr T, et al. Clinical significance of minimal residual disease quantification in adult patients with standard-risk acute lymphoblastic leukemia. Blood. 2006;107(3):1116-1123.

5. Fielding AK, Richards SM, Chopra R, et al. Outcome of 609 adults after relapse of acute lymphoblastic leukemia (ALL); an MRC UKALL12/ ECOG 2993 study. Blood. 2007;109(3):944-950.

6. Paietta E, Li X, Richards S, et al. Implications for the use of monoclonal antibodies in future adult ALL Trials: analysis of antigen expression in 505 B-lineage (B-lin) ALL patients (pts) on the MRC UKALLXII/ ECOG2993 intergroup trial. ASH Annи Meet Abstr. 2008;112:1907.

7. Raponi S, De Propris MS, Intoppa S, et al. Flow cytometric study of potential target antigens (CD19, CD20, CD22, CD33) for antibodybased immunotherapy in acute lymphoblastic leukemia: analysis of 552 cases. Leuk Lymphoma. 2011;52(6):1098-1107.

8. Nagorsen D, Kufer P, Baeuerle PA, Bargou R. Blinatumomab: a historical perspective. Pharmacol Ther. 2012;136(3):334-342.

9. Gabrilovich D, Pisarev V. Tumor escape from immune response: mechanisms and targets of activity. Curr Drug Targets. 2003;4(7):525-536.

10. Kozmik Z, Wang S, Dörfler P, Adams B, Busslinger M. The promoter of the $\mathrm{CD} 19$ gene is a target for the B-cell-specific transcription factor BSAP. Mol Cell Biol. 1992;12(6):2662-2672.

11. Stamenkovic I, Seed B. CD19, the earliest differentiation antigen of the B cell lineage, bears three extracellular immunoglobulin-like domains and an Epstein-Barr virus-related cytoplasmic tail. J Exp Med. 1988;168(3):1205-1210.

12. Tedder TF, Isaacs CM. Isolation of cDNAs encoding the CD19 antigen of human and mouse B lymphocytes. A new member of the immunoglobulin superfamily. J Immunol. 1989;143(2):712-717.

13. Zhou LJ, Ord DC, Hughes AL, Tedder TF. Structure and domain organization of the CD19 antigen of human, mouse, and guinea pig B lymphocytes. Conservation of the extensive cytoplasmic domain. J Immunol. 1991;147(4):1424-1432.

14. Nagorsen D, Baeuerle PA. Immunomodulatory therapy of cancer with T cell-engaging BiTE antibody blinatumomab. Exp Cell Res. 2011;317(9):1255-1260.

15. Carter RH, Tuveson DA, Park DJ, Rhee SG, Fearon DT. The CD19 complex of B lymphocytes. Activation of phospholipase $\mathrm{C}$ by a protein tyrosine kinase-dependent pathway that can be enhanced by the membrane IgM complex. J Immunol. 1991;147(11):3663-3671.

16. Fujimoto M, Fujimoto Y, Poe JC, et al. CD19 regulates Src family protein tyrosine kinase activation in B lymphocytes through processive amplification. Immunity. 2000;13(1):47-57.
17. van Zelm MC, Reisli I, van der Burg M, et al. An antibody-deficiency syndrome due to mutations in the CD19 gene. $N$ Engl J Med. 2006; 354(18):1901-1912.

18. Uckun FM, Sun L, Qazi S, Ma H, Ozer Z. Recombinant human CD19-ligand protein as a potent anti-leukaemic agent. Br J Haematol. 2011;153(1):15-23.

19. Landmeier S, Altvater B, Pscherer S, et al. Cytotoxic T cells transduced with chimeric anti-CD19 receptors prevent engraftment of primary lymphoblastic leukemia in vivo. Leukemia. 2010;24(5):1080-1084.

20. Press OW, Farr AG, Borroz KI, Anderson SK, Martin PJ. Endocytosis and degradation of monoclonal antibodies targeting human B-cell malignancies. Cancer Res. 1989;49(17):4906-4912.

21. Stanciu-Herrera C, Morgan C, Herrera L. Anti-CD19 and antiCD22 monoclonal antibodies increase the effectiveness of chemotherapy in Pre-B acute lymphoblastic leukemia cell lines. Leuk Res. 2008; 32(4):625-632.

22. Ghetie MA, Ghetie V, Vitetta ES. Anti-CD19 antibodies inhibit the function of the P-gp pump in multidrug-resistant B lymphoma cells. Clin Cancer Res. 1999;5(12):3920-3927.

23. Ghetie MA, Picker LJ, Richardson JA, Tucker K, Uhr JW, Vitetta ES. Anti-CD19 inhibits the growth of human B-cell tumor lines in vitro and of Daudi cells in SCID mice by inducing cell cycle arrest. Blood. 1994;83(5):1329-1336.

24. Baracho GV, Miletic AV, Omori SA, Cato MH, Rickert RC. Emergence of the PI3-kinase pathway as a central modulator of normal and aberrant B cell differentiation. Curr Opin Immunol. 2011;23(2):178-183.

25. Bargou R, Leo E, Zugmaier G, et al. Tumor regression in cancer patients by very low doses of a T cell-engaging antibody. Science. 2008; 321(5891):974-977.

26. Brischwein K, Parr L, Pflanz S, et al. Strictly target cell-dependent activation of T cells by bispecific single-chain antibody constructs of the BiTE class. J Immunother. 2007;30(8):798-807.

27. Thakur A, Lum LG. Cancer therapy with bispecific antibodies: clinical experience. Curr Opin Mol Ther. 2010;12(3):340-349.

28. Hoffmann P, Hofmeister R, Brischwein K, et al. Serial killing of tumor cells by cytotoxic $\mathrm{T}$ cells redirected with a CD19-/CD3-bispecific single-chain antibody construct. Int J Cancer. 2005;115(1):98-104.

29. Dreier T, Lorenczewski G, Brandl C, et al. Extremely potent, rapid and costimulation-independent cytotoxic T-cell response against lymphoma cells catalyzed by a single-chain bispecific antibody. Int $J$ Cancer. 2002;100(6):690-697.

30. Löffler A, Kufer P, Lutterbüse R, et al. A recombinant bispecific single-chain antibody, CD19 x CD3, induces rapid and high lymphoma-directed cytotoxicity by unstimulated T lymphocytes. Blood. 2000;95(6):2098-2103.

31. Offner S, Hofmeister R, Romaniuk A, Kufer P, Baeuerle PA. Induction of regular cytolytic $\mathrm{T}$ cell synapses by bispecific single-chain antibody constructs on MHC class I-negative tumor cells. Mol Immunol. 2006;43(6):763-771.

32. Löffler A, Gruen M, Wuchter C, et al. Efficient elimination of chronic lymphocytic leukaemia B cells by autologous $\mathrm{T}$ cells with a bispecific anti-CD19/anti-CD3 single-chain antibody construct. Leukemia. 2003; 17(5):900-909

33. Brandl C, Haas C, d'Argouges S, et al. The effect of dexamethasone on polyclonal $\mathrm{T}$ cell activation and redirected target cell lysis as induced by a CD19/CD3-bispecific single-chain antibody construct. Cancer Immunol Immunother. 2007;56(10):1551-1563.

34. Dreier T, Baeuerle PA, Fichtner I, et al. T cell costimulus-independent and very efficacious inhibition of tumor growth in mice bearing subcutaneous or leukemic human B cell lymphoma xenografts by a CD19-/ CD3-bispecific single-chain antibody construct. J Immunol. 2003; 170(8):4397-4402.

35. Klinger M, Brandl C, Zugmaier G, et al. Immunopharmacologic response of patients with B-lineage acute lymphoblastic leukemia to continuous infusion of T cell-engaging CD19/CD3-bispecific BiTE antibody blinatumomab. Blood. 2012;119(26):6226-6233. 
36. Topp MS, Goekbuget N, Zugmaier G, et al. Anti-CD19 BiTE blinatumomab induces high complete remission rate and prolongs overall survival in adult patients with relapsed/refractory B-precursor acute lymphoblastic leukemia (ALL). ASH Annu Meet Abstr. 2012;120:670.

37. Topp MS, Gökbuget N, Zugmaier G, et al. Long-term follow-up of hematologic relapse-free survival in a phase 2 study of blinatumomab in patients with MRD in B-lineage ALL. Blood. 2012;120(26):5185-5187.
38. Topp MS, Kufer P, Gökbuget N, et al. Targeted therapy with the T-cellengaging antibody blinatumomab of chemotherapy-refractory minimal residual disease in B-lineage acute lymphoblastic leukemia patients results in high response rate and prolonged leukemia-free survival. J Clin Oncol. 2011;29(18):2493-2498.

39. Cheson BD, Pfistner B, Juweid ME, et al. Revised response criteria for malignant lymphoma. J Clin Oncol. 2007;25(5):579-586.

\section{Publish your work in this journal}

Clinical Pharmacology: Advances and Applications is an international, peer-reviewed, open access journal publishing original research, reports, reviews and commentaries on all areas of drug experience in humans. The manuscript management system is completely online and includes a very quick and fair peer-review system, which is all easy to use.
Visit http://www.dovepress.com/testimonials.php to read real quotes from published authors. 